\title{
GESTÃO DA INOVAÇÃO EM EMPRESAS DO SETOR COUREIRO-CALÇADISTA
}

Management of innovation in companies of the leather-footwear sector

Vanessa Theis

E-mail: nessa.theis@gmail.com

Doutora e Mestre em Qualidade Ambiental pela Universidade Feevale; pós-doutoranda em Indústria Criativa pela Universidade Feevale.

Endereço para contato: ERS-239, 2755, 93525-075, Novo Hamburgo, Rio Grande do Sul, Brasil. https://orcid.org/0000-0002-5100-7574

Camila Fernanda Blos

E-mail: cfbols@gmail.com

Pós-graduada em Inovação e Estratégia Empresarial pela Universidade Feevale; Graduada em Comércio Exterior pela Universidade do Vale do Rio dos Sinos. https://orcid.org/0000-0001-6815-3458

Dusan Schreiber

E-mail: dusan@feevale.br

Doutor em Administração pela Universidade Federal do Rio Grande do Sul; Mestre em Administração pela Universidade do Vale do Rio dos Sinos. Professor e Pesquisador no PPG em Qualidade Ambiental e no Mestrado em Indústria Criativa da

Universidade Feevale. http://orcid.org/0000-0003-4258-4780 


\section{Resumo}

As mudanças no cenário econômico vêm transformando o modo de atuação das empresas, e, com isso, a inovação têm sido uma forte aliada para se manterem competitivas no mercado. Pensando na realidade das organizações localizadas na Cidade de Novo Hamburgo, no Estado do Rio Grande do Sul, que durante muito tempo teve sua economia voltada para o setor coureiro-calçadista, este artigo objetivou identificar as especificidades, necessidades e carências do processo de gestão da inovação em empresas do referido setor. Para atender ao exposto, optou-se pelo delineamento metodológico, que iniciou com a revisão bibliográfica e a coleta de dados por meio de observações diretas e entrevista em profundidade com nove gestores de diferentes organizações. Evidenciou-se que as referidas organizações ainda se encontram em estágios iniciais no que diz respeito ao processo de gestão da inovação. Contudo, os entrevistados reconhecem o potencial de diferenciação que está implícito no processo de inovação, mas ressaltam o alto custo, a pouca experiência e a falta de cultura da inovação como as principais barreiras na adoção de práticas de inovação.

Palavras-chave: Inovação. Gestão. Setor coureiro-calçadista.

\section{Abstract}

The changes in the economic scenario have transformed the mode how companies operate, and with that, innovation has been a strong ally to keep themselves competitive in the market. Thinking about the reality of organizations located in the city of Novo Hamburgo, in the state of Rio Grande do Sul, which for a long time had its economy turned to the leather footwear sector, this article aimed to identify the specificities, needs and lacks of the innovation management process in companies in that sector. A bibliographic review was carried out and data were collected with direct observations and in-depth interview with nine managers from different organizations. It was pointed out that these organizations are still in the early stages of the innovation management process. However, respondents recognize the potential for differentiation that is implicit in the innovation process, but emphasize that high cost, little experience and lack of innovation culture as the main barriers in adopting innovation practices.

Keywords: Innovation. Management. Leather-footwear sector.

\section{INTRODUÇÃO}

Dados da Associação Brasileira das Indústrias de Calçados (Abicalçados) (2020) revelam que o ano de 2019, mesmo diante de todas as dificuldades impostas nos mercados internacional e doméstico, foi de estabilidade para o setor. E entidade aponta um crescimento de $0,4 \%$, contabilizando 908,2 milhões de pares produzidos no ano, o que coloca o Brasil como quarto maior produtor de calçados do mundo. No mesmo ano, os embarques, em volume, cresceram 1,5\% ante 2018. Especificamente para os Estados Unidos, as exportações cresceram $11 \%$ no período. A avaliação é de que a guerra comercial instalada entre os norte-americanos e a China teve papel fundamental no resultado, já que os compradores estadunidenses acabaram buscando fornecedores fora do mercado chinês, como forma de evitar as altas tarifas de importação impostas pelo Ex-presidente Donald Trump. 
O nível de utilização da capacidade instalada da indústria de calçados no Brasil está em processo de queda desde 2014. Em 2019, observa-se uma pequena recuperação desse indicador (76,9\%) quando comparado com os anos anteriores - $2018(76,0 \%)$ e 2017 (75,0\%). No entanto, ao se comparar com a utilização da capacidade instalada de 2014 (78,5\%), tem-se uma realidade de baixa utilização do parque fabril do setor de calçados. Contudo, conforme dados divulgados pela Abicalçados (2021), o setor perdeu mais de $20 \%$ da sua produção em 2020, retornando a patamares de 16 anos atrás. Na exportação a queda foi de $18,6 \%$, pior número desde 1983. Para 2021, a estimativa é de incremento de $14 \%$ na produção em relação a 2020, semelhante à produção de 10 anos atrás, em razão do forte impacto da pandemia no mercado.

Ao estabelecer uma segmentação regional da produção de calçados brasileira, constata-se uma participação significativa do Nordeste. Porém, a partir de 2017, verifica-se uma queda nessa participação; apenas neste último ano a produção da região, em volume, reduziu $6,6 \%$. Por consequência, as regiões Sul e Sudeste aumentam a importância na produção de calçados no Brasil, com destaque para o Sudeste, que vem crescendo a um ritmo mais acelerado que o Sul. A região Centro-Oeste apresentou a maior variação na produção, com um incremento de $26,8 \%$, porém sua representatividade ainda é pequena, com $0,8 \%$ do total da produção brasileira de calçados. Quanto aos Estados Ceará, Rio Grande do Sul e Minas Gerais, estes figuram entre os três maiores produtores de calçados em quantidade de pares, com participação de mercado de 26,5\%, 22,1\% e 17,5\%, respectivamente, no ano de 2019 (Abicalçados, 2020).

Ressalta-se que a indústria calçadista nacional tem sido pressionada pelos produtos asiáticos, de qualidade similar, contudo mais econômicos, e pelos produtos italianos, de preço mais elevado, mas com melhor imagem no mercado internacional. Na busca de mão de obra mais econômica e obtenção de benefícios fiscais, algumas empresas passaram a se deslocar do Rio Grande do Sul para regiões de maior oferta de mão de obra, principalmente para - Nordeste, bem como frequentemente afastadas das capitais e sem tradição na produção de calçados (Santana et al., 2020). Esse processo se caracterizou pela transferência de unidades de produção, predominantemente, de artigos mais econômicos, ficando na sede das empresas a produção de artigos mais elaborados, assim como as áreas estratégicas.

Alinhado a essa mudança de paradigmas, fica clara a importância de direcionar os esforços do país na inserção, geração e disseminação de tecnologia e inovação para o setor coureiro-calçadista brasileiro (Bessi et al., 2019). Nesse sentido, os autores Souza et al. (2012) destacam os clusters, que favorecem o intercâmbio de informações e formas colaborativas de produção. A indústria calçadista brasileira é constituída por clusters, dentre os quais se destacam o Vale do Sinos e Paranhana, no Rio Grande do Sul, Jaú, Birigui e Franca, em São Paulo, e Nova Serrana, em Minas Gerais. Dados da Abicalçados (2020) revelam 
que o polo calçadista do Vale dos Sinos representa 45,1\% da produção do Estado, ou seja, aproximadamente 90,4 milhões de pares.

Ante o exposto, e, considerando que a inovação proporciona as condições de permanência das empresas no mercado, bem como a fonte para a concepção do diferencial competitivo, este artigo tem como objetivo identificar as especificidades, necessidades e carências do processo de gestão da inovação em empresas do setor coureiro-calçadista localizadas no Município de Novo Hamburgo, no Estado do Rio Grande do Sul, Brasil. Em termos metodológicos, este estudo caracteriza-se como descritivo, com abordagem qualitativa e estudo de casos múltiplos, sendo os dados obtidos por meio de entrevista em profundidade com nove gestores de diferentes organizações.

A estrutura do trabalho inicia pela revisão da literatura acerca da gestão da inovação, sendo sequenciado pela contextualização dos procedimentos metodológicos empregados para a coleta de evidências e seu devido tratamento. Na análise, capítulo seguinte, são apresentados os resultados, à luz das vertentes teóricas abordadas. Considerações finais e referências encerram o presente trabalho.

\section{GESTÃO DA INOVAÇÃO}

A inovação, fenômeno que contempla iniciativas individuais e/ou coletivas de criação de valor e de mudanças organizacionais, é considerada elemento potencial para a geração de vantagens competitivas e construção do desenvolvimento econômico (Davila et al., 2018). Com um mercado cada dia mais competitivo, as empresas buscam maneiras de reduzir seus custos e aumentar os lucros. Por isso, a capacidade de inovar é vista como uma vantagem competitiva para a grande maioria das empresas, permitindo-lhes gerar riqueza contínua e manter-se à frente da concorrência (Thomas \& Engesser, 2012).

Nesse sentido, Frishammar et al. (2019), corroboram que a inovação é o elemento essencial para as organizações alavancarem o crescimento e contribuirem com o aumento das receitas. Entretanto, West e Bogers (2017) elencam que para inovar é importante identificar oportunidades e sinais de mudança, para tomar as decisões corretas em relação ao futuro das organizações. Assim, Xavier et al. (2017) sinalizam que, no ritmo intenso, em que há o surgimento de novos produtos, processos e serviços, as organizações necessitam ser capazes de gerar e implementar novas práticas, fazer algo novo, com o uso de diferentes estruturas e ferramentas gerenciais, de modo a adaptar-se a novas realidades dos consumidores ou antecipar-se às mudanças do ambiente externo.

Cumpre destacar que os conceitos sobre os ciclos econômicos, expressados pelo economista Schumpeter (1982), são relevantes para a atual ciência econômica. De acordo como o autor, o que provoca a alteração no estado de equilíbrio econômico, avançando para 
um processo de expansão, é o surgimento de alguma inovação. Para ele, a abertura de novos mercados, a criação de novos bens e serviços, a descoberta de um novo método de produção ou comercialização, o uso de novas tecnologias ou a alteração da estrutura do mercado vigente são indicadores de inovação.

Para Tidd e Bessant (2015), a inovação é orientada pela habilidade de fazer relações, de visualizar oportunidades e de tirar vantagem destas. A capacidade de distinguir oportunidades e criar novas formas de explorá-las é indispensável ao processo de inovação e envolve possibilidades inteiramente novas, como a exploração de avanços tecnológicos totalmente radicais. Todavia, a inovação não só requer a abertura de novos mercados, ela exige a implementação de novas formas de servir àqueles já estabelecidos e maduros.

Diferente dos conceitos de inovação discutidos, como a abertura de novos mercados ou a alteração da estrutura dos negócios já existentes, o Manual de Oslo, elaborado pela Organização para Cooperação e Desenvolvimento Econômico (OCDE) (2005), discute como a inovação pode ocasionar mudanças no nível da empresa individual. Assim, concentra-se em processos e produtos significativamente aprimorados, reconhecendo que as inovações organizacionais podem resultar em melhoras significativas no desempenho das empresas.

Evidencia-se que a percepção de que a tecnologia desempenha um papel de vital importância no desenvolvimento da inovação é comum aos autores Tidd e Bessant (2015), bem como aos membros da OCDE (2005). Além disso, as oportunidades tecnológicas são reconhecidas e exploradas de maneiras distintas entre as empresas, visto que os colaboradores são considerados um "recurso-chave de uma empresa inovadora." (OCDE, 2005, p. 41). Ressalta-se que, na indústria brasileira, o desenvolvimento e a absorção de tecnologia, por meio da aquisição de máquinas e equipamentos, continuam sendo a atividade de maior relevância atribuída à inovação, segundo os resultados evidenciados pela PINTEC (Instituto Brasileiro de Geografia e Estatística [IBGE], 2014).

Percebe-se que gerir uma empresa é uma tarefa que se desenvolve em duas dimensões distintas. Há a gestão diária, constituída por decisões que aperfeiçoam o processo de forma constante e que faz as coisas acontecerem. Mas, também, existe um segundo tipo de gestão, em que o administrador inventa o futuro, desenvolve cenários e procura por novas ideias, visando modificar a maneira como as coisas são vistas. Nesse contexto, a mudança de realidade é um processo contínuo que desafia toda a equipe, sendo alimentada por ideias práticas e sugestões úteis. Portanto, a inovação é uma abordagem mediante a qual uma equipe consegue mudar a realidade (Brabandere, 2006).

Para ocorrer essa mudança, modifica-se primeiro a percepção do colaborador diante da nova realidade. Essa percepção Brabandere (2006) associou com a criatividade quando ponderou que esta é o modo como o indivíduo consegue êxito em mudar a sua percepção. Vilha (2010) corrobora que é preciso estimular e gerir os processos inovativos de dentro das 
empresas, a partir de discussões sobre as possibilidades de mudanças técnicas, intensificando a troca de informações tecnológicas e as relações de parceria com os diversos atores que interagem com as empresas.

Para Davila et al. (2012), a inovação inclui a gestão de grandes volumes de criatividade. Na realidade, equilibrar e impulsionar as tensões inerentes entre criatividade e comercialização demanda uma clara estratégia de inovação, processos bem definidos e sólida liderança. Sem a intervenção da administração, a criatividade acaba impedindo o avanço da comercialização ou vice-versa. Por conseguinte, a criatividade propicia o desenvolvimento de novos conceitos, aperfeiçoando a maneira de fazer as coisas, e ao ser executada, transforma ideias criativas em realidades comercialmente viáveis.

Zawislak et al. (2008) definem a inovação como a aplicação de conhecimento para gerar mudanças organizacionais e técnicas que são capazes de ofertar vantagens para as empresas que as utilizam. Para eles, inovação é a aplicação de conhecimento novo para a empresa, e não necessariamente novo para as demais empresas, dessa forma, pequenas e incrementais mudanças são muito mais habituais do que as mudanças radicais. Cumpre destacar que para Jannuzzi et al. (2016), a inovação possui relação direta com o conhecimento. Os autores acreditam que inovação, conhecimento e informação formam um tripé fundamental para a competitividade de qualquer organização, na medida em que toda inovação, independente de classificação, traz em sua essência a geração, o uso e a assimilação de conhecimentos e informações.

De acordo com Oliveira et al. (2009), existem limitações de longo prazo para quaisquer técnicas novas de produção, transporte, distribuição, produtividade e eficiência. Para suprir essas limitações, o fluxo de novas ideias científicas, invenções e inovações é estimulado através de instituições especializadas, como centros de pesquisa e desenvolvimento. Os autores Trantopoulos et al. (2017) destacam que os centros de pesquisa são responsáveis por estimular a inovação nas empresas, buscando oportunidades e promovendo inovações que possam gerar resultados positivos para as organizações.

A estratégia de inovação organizacional precisa adaptar-se à situação do negócio $e$ ser transparente para todos os seus membros. A organização deve aplicar seus recursos em áreas estratégicas que proporcionam maior retorno sobre o investimento, do contrário pode afetar a sua capacidade de competir no mercado. A decisão de qual estratégia de inovação melhor se adapta à situação da concorrência externa e do mercado e às condições internas da empresa constitui responsabilidade da equipe de altos executivos, e em última análise é tarefa do diretor geral (Davila et al., 2012).

Nos cenários competitivos em rápida modificação, os processos internos não podem ser estáticos. A dinâmica do mercado determina a velocidade da mudança nos modelos de negócios e na estratégia. Nesse conjunto de interações, a inovação responde continuamente 
às demandas, comportamentos e experiência dos consumidores. A fim de criar uma estrutura facilitadora da inovação, as empresas precisam estabelecer conexões explícitas entre estratégia, modelos de negócios e processos internos (Prahalad \& Krishnan, 2008).

Scherer e Carlomagno (2009) complementam que a inovação é um processo que deve ser gerenciado e, para tal, deve estar vinculada à estratégia corporativa adotada pela empresa. Igualmente, Tidd e Bessant (2015) afirmam que as organizações precisam ter definida, claramente, a sua estratégia comercial, bem como a forma como a inovação pode contribuir para viabilizá-la. Desse modo, o problema não é a escassez de maneiras de obter vantagem competitiva pela inovação, mas saber quais delas escolher.

Trott (2012) apresentou uma pesquisa que investigou os principais fatores que podem contribuir para o sucesso ou para o fracasso de projetos inovadores dentro das empresas, dividindo-os em quatro grupos: (1) fatores relativos à empresa que englobam herança organizacional, experiência, equipe de $P \& D$, estratégia de inovação, estrutura organizacional e intensidade de $P \& D_{;}$(2) fatores relativos ao projeto que juntam a complementariedade, o estilo de gestão e o apoio da alta administração; (3) fatores relativos ao produto que dizem respeito a preço, qualidade, diferencial e avanço tecnológico; e (4) fatores relativos ao mercado, que tratam da concentração de mercado-alvo, entrada oportuna no mercado, pressão competitiva e marketing; os fatores relativos à empresa e ao projeto estão ligados à viabilidade tecnológica, já os fatores relativos ao produto e ao mercado estão ligados à viabilidade comercial.

Vale destacar que Schumpeter (1982) já sugeria que as organizações devem priorizar as necessidades dos clientes, uma vez que são o fim de toda a cadeia produtiva. Entretanto, via de regra, são as organizações que iniciam o processo de mudança com o lançamento de novos produtos ou os já existentes com utilizações distintas. Assim, os consumidores são influenciados a querer bens novos, ou aqueles "que diferem em um aspecto ou outro daqueles que tinham o hábito de comprar" (Schumpeter, 1982, p. 48).

Sendo assim, é possível afirmar que a competitividade das empresas deriva de sua capacidade de aplicar a tecnologia de modo a lançar novos produtos ou melhorar seus processos. Para isso, é imprescindível fazer investimentos em $P \& D$ e aplicar o conhecimento científico. Contudo, para tal conhecimento ser posto em prática, na maioria das vezes é necessário realizar adaptações e prover soluções complexas. Portanto, para facilitar o processo de inovação, recomenda-se às organizações constituir redes de cooperação, formais e mesmo não formais, capazes de promover a interação entre empresas, instituições acadêmicas e órgãos governamentais (Coral et al., 2009; Guimarães, 2011).

Nessas redes desenvolvem-se diversas formas de intercâmbios, como "acordos para realização de $P \& D$, uso compartilhado de banco de dados, licenciamentos cruzados e parcerias com objetivos múltiplos" (Barbieri et al., 2009, p. 29). Essa maneira de criar e gerir a 
inovação tem como pressuposto a existência de um ambiente de alta sincronia e paralelismo entre as diversas etapas do processo de inovação, uma vez que elas devem ser difundidas para todas as instituições envolvidas. Para tanto, faz-se necessário um ambiente de alta conectividade que permita administrar o fluxo intenso de informações e conhecimentos de naturezas diversas (Barbieri et al., 2009).

\section{PROCEDIMENTOS METODOLÓGICOS}

Para compreender e descrever os fenômenos existentes no ambiente organizacional, a fim de gerar conhecimento para aplicação prática, os pesquisadores devem ter dados (Hair et al., 2005). Nesse sentido, os dados da pesquisa foram coletados a partir de narrativas com gestores da unidade de análise, com base na necessidade de entender a percepção dessas pessoas sobre o universo organizacional. Julgou-se esse procedimento essencial para realizar a análise à luz da revisão teórica e facultar a identificação de categorias de análise.

Foram realizadas entrevistas semiestruturadas, as quais se utilizam de questões abertas, que permitem ao entrevistador entender e captar a perspectiva dos participantes da pesquisa (Roesch, 2005). Para a realização das entrevistas, foram selecionadas nove empresas do setor coureiro-calçadista da Cidade de Novo Hamburgo, no Estado do Rio Grande do Sul, de forma não probabilística, intencional e por conveniência, adotando critérios de acessibilidade e disponibilidade de tempo dos entrevistados.

As entrevistas formam realizadas com nove gestores, de diferentes organizações, sendo todas do setor coureiro-calçadista, englobando desde fabricantes de componentes até o calçado final. As entrevistas foram gravadas e transcritas no prazo máximo de seis horas após o evento. Como o formato da transcrição resulta, normalmente, em um texto não linear e até mesmo confuso, a entrevista foi reescrita na forma de um texto coeso, em formato de narrativa (Polkinghorne, 2007). Na sequência foi submetida à apreciação da pessoa entrevistada, para conferência, ajustes ou contribuições. $O$ perfil de cada entrevistado pode ser visualizado na Tabela 1:

Tabela 1

Perfil dos entrevistados

\begin{tabular}{lllll}
\hline Entrevistado & Sexo & $\begin{array}{c}\text { Idade } \\
\text { (anos) }\end{array}$ & Formação acadêmica & Cargo \\
\hline E1 & Feminino & 35 & Mestre em Processos Industriais & Gerente de desenvolvimento \\
\hline E2 & Masculino & 29 & Bacharel em Administração & $\begin{array}{l}\text { Coordenador de pesquisa e desen- } \\
\text { volvimento }\end{array}$ \\
\hline E3 & Masculino & 42 & Bacharel em Administração & Diretor \\
\hline
\end{tabular}




\begin{tabular}{lllll}
\hline Entrevistado & Sexo & $\begin{array}{l}\text { Idade } \\
\text { (anos) }\end{array}$ & \multicolumn{1}{c}{ Formação acadêmica } & Cargo \\
\hline E4 & Masculino & 31 & $\begin{array}{l}\text { Mestre em Engenharia de Produ- } \\
\text { ção }\end{array}$ & $\begin{array}{l}\text { Gerente de desenvolvimento de } \\
\text { produto }\end{array}$ \\
\hline E5 & Feminino & 34 & $\begin{array}{l}\text { Pós-graduada em Marketing } \\
\text { Estratégico }\end{array}$ & Coordenadora de marketing \\
\hline E6 & Masculino & 48 & $\begin{array}{l}\text { Pós-graduado em Gestão Empre- } \\
\text { sarial }\end{array}$ & Diretor \\
\hline E7 & Feminino & 35 & Bacharel em Comércio Exterior & Gerente comercial \\
\hline E9 & Masculino & 51 & Técnico em Calçado & Diretor \\
\hline
\end{tabular}

Com o propósito de identificar especificidades, necessidades e carências do processo de gestão da inovação do setor coureiro-calçadista, durante a entrevista, os gestores foram questionados com relação aos aspectos que tangem ao referido processo. Dentre as perguntas, destacam-se:

a) O que é inovação ou o que é um produto inovador?

b) Como a sua empresa inova? Sua empresa estimula as pessoas a inovarem?

c) Quais resultados a empresa obteve, nos últimos cinco anos, a partir das práticas de inovação?

d) Quais são as pessoas, dentro da empresa, responsáveis pelo processo de inovação?

e) Como as pessoas, dentro da empresa, são capacitadas para inovar?

f) Como a empresa estimula as pessoas a inovarem?

g) Quais são os principais obstáculos à inovação?

h) Como a empresa inseriu a inovação em seu plano estratégico e relacionou-o com metas e objetivos?

i) Como a alta administração se engaja no desenvolvimento da inovação?

As perguntas foram construídas com base na revisão teórica e validadas por um especialista, doutor em administração e consultor empresarial. Essa forma de validação é recomendada por autores que versam sobre metodologia em pesquisa, como Marconi e Lakatos (2011). As entrevistas foram realizadas individualmente com cada entrevistado, em ambiente isolado.

O teor da entrevista foi submetido à análise de conteúdo, que, segundo Bardin (2016), refere-se a um conjunto de técnicas de análise das comunicações que utiliza procedimentos sistemáticos e objetivos de descrição do conteúdo das mensagens. Esse método consiste 
em procedimentos para levantar inferências válidas a partir do texto, buscando classificar palavras, frases, ou mesmo parágrafos em categorias de conteúdo. De forma sucinta, a análise categorial consiste na análise dos textos obtidos das transcrições das entrevistas, isto é, a organização e a síntese dos dados qualitativos resultam na obtenção de categorias que contêm a essência do discurso dos entrevistados.

De acordo com Bardin (2016), as categorias podem ser criadas a priori ou a posteriori, isto é, a partir da teoria ou após a coleta de dados. No caso desta pesquisa, as categorias de análise foram criadas a priori, norteando-se pelos conceitos definidos no referencial teórico acerca da temática de inovação. Assim, os dados coletados nas entrevistas foram analisados por meio da análise categorial, que, conforme Bardin (2016), consiste no desmembramento do texto em categorias agrupadas analogicamente. Dessa forma, a interpretação dos dados foi realizada pelo método de análise de conteúdo, respaldada pela observação in loco.

\section{ANÁLISE E DISCUSSÃO DOS RESULTADOS}

A inovação ainda é um tema muito recente para grande parte das empresas que integram o sistema coureiro-calçadista. Conforme definido pelo Manual de Oslo (OCDE, 2005) a inovação pode ser caracterizada como a implementação de um novo produto, serviço, processo ou método de marketing e organizacional. Apesar do pouco conhecimento, é perceptível o interesse dos empresários nesse tema, os quais definem inovação como algo que é feito para "melhorar significativamente" um produto, serviço ou processo e que gere valor para a empresa.

Apesar de todas as empresas entrevistadas fazerem parte do mesmo setor, cada uma possui um perfil diferente, o que pode ser claramente visualizado por meio do tipo de inovação com que elas trabalham. Nesse sentido, E4 relatou que na sua empresa "pode-se ver a inovação nas melhorias que são realizadas nos processos fabris, principalmente àqueles atrelados à redução de resíduos ou para atender um problema que surge ... Estamos sempre pensando em como podemos reduzir custos, e isso resulta em inovação" (15 de julho de 2019). E8, por seu turno, relata que "a nossa principal inovação se origina do desenvolvimento de novos produtos... desenvolvemos novos produtos para atender novos clientes ... e isso resulta em vendas para clientes diferentes [...] resulta em dinheiro" (19 de julho de 2019).

Conforme o Manual de Oslo (OCDE, 2005), a inovação em processos diz respeito à implementação ou à melhoria de algum método já utilizado. Esse é o tipo de inovação que ocorre na empresa do entrevistado E4. Nessa organização, a inovação é focada principalmente na melhoria de processos que já existem, mas que apresentam algum tipo de problema. $\mathrm{Na}$ empresa do entrevistado E8, as inovações possuem foco no desenvolvimento de novos produtos, com objetivo de criarem novas demandas no mercado. Para Schumpeter (1982), 
é por meio desses novos mercados, produtos e serviços que são rompidos os paradigmas econômicos, sendo possível obter um desenvolvimento da economia no longo prazo.

Segundo o Manual de Oslo (OCDE, 2005), as atividades de inovação dentro da empresa vão depender da relação direta que possui com suas fontes de informação, conhecimento, tecnologias, práticas e recursos humanos e financeiros. É possível identificar que grande parte das empresas entrevistadas possui dificuldade em incorporar essas novas atividades dentro de seus próprios sistemas operacionais e gerenciais. Dessa forma, elas não possuem setores, áreas ou pessoas específicas que coordenem a inovação. A seguir, observam-se os comentários que remetem a essa interpretação:

Sobre a inovação. Ainda não temos uma equipe de inovação... O tema é novo, estamos aprendendo. ... A concorrência nos obrigou a aprender às pressas.... Ainda não temos ninguém olhando apenas para a inovação. Penso que ainda estamos construindo nossa identidade quanto à inovação (E3, 12 de julho de 2019).

A gente (se referindo ao time de marketing) está sempre buscando a melhor forma de vender . . de mostrar o valor do nosso produto. ... Não tem ninguém com o título de "responsável pela inovação", mas eu vejo que todos fazemos um pouquinho pela inovação, só não está formalizado (E5, 17 de julho de 2019).

A inovação acontece no dia a dia. ... Não tem ninguém que fica cobrando resultado de inovação. . .. O que eu vejo na equipe é que todos estão sempre buscando por melhores práticas, e isso resulta em inovação. ... Não acho que precisa ser algo grandioso para ser inovação. .. O que está nos faltando, talvez, seria formalizar a inovação, para que seja algo contínuo por toda a empresa (E9, 22 de julho de 2019).

Eu acho que o setor que mais pensa em inovação é a área de desenvolvimento criativo, pois o trabalho deles é pensar diferente ... de buscar o novo. Lá (se referindo ao setor) se ouve falar muito em inovação. . . No restante da empresa se busca uma melhor forma de desenvolver o trabalho ... o que no final das contas também é inovação, mas é todo informal (E7, 19 de julho de 2019).

Conforme Zawislak et al. (2008), a inovação é a geração de um novo conhecimento para a empresa em questão, e não necessariamente novo para as demais empresas. Com isso, é muito mais comum haver pequenas e incrementais mudanças do que inovações radicais dentro das organizações. Essa afirmação é concretizada através da verificação de que grande parte das inovações nas empresas, conforme pôde ser verificado nos relatos explanados pelos entrevistados, ocorre por meio da busca de soluções para problemas específicos de clientes, do mercado ou de questões internas. Ou seja, como não existem setores responsáveis pelo gerenciamento da inovação, são poucas as empresas que trabalham de forma proativa para gerar inovações por motivações diferentes destas. 
De acordo com Tidd e Bessant (2015), as empresas devem criar um ambiente favorável à inovação, atuando na busca de novas oportunidades, orientando os funcionários e criando uma cultura de inovação, além de difundir novos conhecimentos. Com base nos relatos, podese verificar que as organizações do setor coureiro-calçadista já estão atentas quanto às suas limitações e particularidades a respeito da inovação e estão cientes da necessidade de buscar maneiras de estimular seus colaboradores a pensarem em inovação. Os entrevistados E2, E4 e E9 são estimulados a inovar, principalmente, através da participação em palestras e eventos relacionados ao tema Inovação, a fim de buscar informações complementares que auxiliem nesse processo.

Para que as estratégias de inovação sejam bem-sucedidas, é necessário realizar atividades que privilegiem a inovação. Para isso, é desejável estimular a geração de ideias e o desenvolvimento de projetos de inovação, além de estruturar um sistema de gestão do conhecimento (Brabandere, 2006). A empresa do entrevistado El encontrou uma maneira contínua e eficaz de estimular a inovação, por meio de um programa de ideias, no qual são realizadas campanhas que incentivam os colaboradores a postarem ideias, e premiando semestralmente o colaborador que tiver o maior número de ideias apresentadas, bem como o gestor com maior número de ideias implementadas.

Todos são responsáveis por inovar. ... A gente reuniu os gerentes e diretores para discutir como poderíamos fazer da inovação algo recorrente na empresa. . . Aí então se criou um programa de ideias. ... A alta direção, a área de gestão de projetos e o comitê avaliador do programa de ideias são os responsáveis por motivar os colaboradores, buscar tecnologias, observar o mercado e favorecer a inovação.

... na política de portas abertas, a gente delimitou que todos os gestores são responsáveis pelos processos de inovação em suas áreas. . . os gestores são os responsáveis por motivar os funcionários a dar ideias e contribuir com as campanhas específicas (El, 9 de julho de 2019).

Essa ação corrobora Brabandere (2006), Davila et al. (2012) e Vilha (2010), que sinalizam a necessidade de estimular e gerir processos inovativos dentro das empresas, criando espaços internos de discussão sobre as possibilidades de mudanças e intensificar a troca de informações entre os próprios colaboradores. Com relação aos estímulos para inovar, alguns entrevistados destacam:

Eu acredito que a inovação não se origina do nada. . . Ninguém inova sozinho na sua bolha. . . É preciso pensar coletivo. .. Não adianta a gente ter um centro de pesquisa específico para o setor calçadista aqui do nosso lado, se gerentes não estiverem alinhados com este objetivo.... Ou melhor, não adianta toda uma estrutura de pesquisa, se o diretor, eu, no caso, não incentivar e cobrar do meu pessoal (E6, 17 de julho de 2019). 
Se tu incentiva a inovação, então tu possibilita que as pessoas pensem da mesma forma ... pensando na forma da inovação ... em como criar produtos novos, em novas ideias, novos jeitos de fazer as coisas (E3, 12 de julho de 2019).

Verifica-se que o entrevistado E6 salientou a importância desse estímulo, pois de nada adianta os institutos e centros de pesquisa estarem focados em oxigenar ideias se as empresas não estão alinhadas a esse objetivo. De acordo com o entrevistado E3, essas práticas de incentivo à inovação estão proporcionando para a empresa a formação de grupos de pessoas com pensamento sistêmico e inovador, que estão sempre observando oportunidades e prontas para propor e implementar novas ideias.

Existem limitações de longo prazo para a implementação de qualquer novo método, técnica, produto e processo (Oliveira et al., 2009), o que pode ser claramente entendido quando as empresas são questionadas sobre as suas principias inovações geradas nos últimos cinco anos. Poucas empresas puderam apresentar resultados concretos, pois a maioria delas está trabalhando com o tema inovação há menos tempo do que cinco anos e, dessa forma, não conseguiram ainda mensurar os resultados específicos que elas apresentam.

Como parte das empresas não possui um programa ou setor específico que controle as inovações, elas acabam entrando nos resultados diários da empresa assim que geram valor, dessa forma, é difícil para as empresas saberem quais são os resultados específicos de cada inovação. Mesmo com essa falta de um controle mais eficaz, o entrevistado E2 acredita que as inovações são as grandes responsáveis pelo atual resultado positivo da empresa em meio a toda a crise econômica do país, sejam essas inovações realizadas em processos internos, nos produtos e nos serviços oferecidos aos clientes. Tal constatação complementa os autores Thomas e Engesser (2012), que afirmam que em um mercado cada vez mais competitivo, as empresas precisam buscar maneiras de reduzir os custos e aumentar seus lucros, assim, a capacidade de inovar é vista como uma vantagem competitiva, permitindolhes gerar riquezas e manter-se à frente da concorrência.

Com relação à capacitação, praticamente todos os entrevistados mencionaram que as empresas proporcionam e incentivam suas participações em seminários, feiras, palestras, workshops, fóruns e demais eventos que tenham correlação com o tema Inovação. Essas atividades também foram mencionadas por Vilha (2010), que afirmou que as ações de inovação também devem passar pelo estimulo à inserção dos funcionários em cursos de atualização tecnológica, treinamentos e seminários; intercâmbios entre empresa e instituição de ensino e pesquisa para trocas de informações, experiências e obtenção de conhecimento; e criação de sistemas de incentivo para trabalhadores que realizam cursos técnicos e superiores.

De acordo com Prahalad e Krishnan (2008) e Scherer e Carlomagno (2009), a dinâmica competitiva das empresas que atuam com inovação tecnológica exige excelência 
na condução das operações e pensar na gestão de empresas que têm expressivos desafios que remetem ao controle gerencial - atividade-chave para a gestão das organizações. $O$ controle gerencial direciona o foco para tarefas e auxilia na manutenção da coerência operacional de uma empresa como um todo, permitindo que ela possa perpetuar a sua existência. Alinhado a essa afirmação, as empresas em estágio um pouco mais avançado já estão inserindo a inovação em seus planejamentos estratégicos, com o objetivo de incorporar atividades específicas a essa prática.

Um exemplo é o entrevistado E5 que afirma que, no planejamento estratégico anterior (2008-2015), a inovação estava subentendida dentro de algumas estratégias corporativas e setoriais, sendo necessário pensar e implementar algo diferente para atingir o resultado esperado. Contudo, no novo planejamento estratégico (2016-2022), a inovação está aparecendo de forma mais explícita, inclusive como citação da necessidade de mais projetos em formato de inovação aberta ou cocriação. $O$ entrevistado E8 ainda salienta que a direção de sua empresa atua desde a concepção da ideia até a implementação dela no mercado.

A fim de sintetizar as evidências decorrentes da análise de dados, a Tabela 2 expõe as percepções dos entrevistados sobre a inovação de produtos e processos, bem como sobre dificuldades, desafios e tendências relacionados à inovação no segmento de produção de couros e calçados.

Tabela 2

Inovação de produtos e processos em organizações industriais do setor coureiro-calçadista

\begin{tabular}{lll}
\hline \multicolumn{1}{c}{ Categorias de análise } & \multicolumn{1}{c}{ Resultados da pesquisa empírica } & Autores de referência \\
\hline Conceito de inovação & $\begin{array}{l}\text { Melhorar significativamente um produto, } \\
\text { serviço ou processo e que gere valor para a } \\
\text { empresa. }\end{array}$ & OCDE, 2005 \\
\hline Inovação em processos & $\begin{array}{l}\text { Melhoria de processos que já existem na } \\
\text { empresa, mas que apresentam algum tipo de } \\
\text { problema. }\end{array}$ & $\begin{array}{l}\text { OCDE, } 2005 \\
\text { Schumpeter, } 1982\end{array}$ \\
\hline Inovação em produtos & $\begin{array}{l}\text { Foco no desenvolvimento de novos produtos } \\
\text { e serviços para criar novas demandas ao } \\
\text { mercado. }\end{array}$ & Schumpeter, 1982 \\
\hline Incorporação da inovação na & $\begin{array}{l}\text { As empresas não possuem setores específicos } \\
\text { para administrar a inovação, incorporando-a } \\
\text { empresa }\end{array}$ & OCDE, 2005 \\
\hline Estímulo à inovação & $\begin{array}{l}\text { Estímulo por meio de programas de ideias e e } \\
\text { campanhas específicas dentro da empresa. }\end{array}$ & Vilha, 2010 \\
\hline Inovação incremental versus & $\begin{array}{l}\text { Grande parte das inovações ocorre através } \\
\text { da busca de soluções para problemas especí- } \\
\text { ficos, não ocorrendo de forma proativa para } \\
\text { gerar novas demandas ao mercado. }\end{array}$ & Zawillak et. al., 2008 \\
\hline
\end{tabular}




\begin{tabular}{|c|c|c|}
\hline Categorias de análise & Resultados da pesquisa empírica & Autores de referência \\
\hline Incentivo à inovação & $\begin{array}{l}\text { Grande parte das empresas é incentivada } \\
\text { por meio da participação em palestras e } \\
\text { eventos relacionados ao tema. }\end{array}$ & Oliveira et al., 2009 \\
\hline Resultados das inovações & $\begin{array}{l}\text { Poucas empresas podem apresentar resulta- } \\
\text { dos gerados através de inovações nos últimos } \\
\text { cinco anos. }\end{array}$ & Oliveira et al., 2009 \\
\hline Vantagem competitiva & $\begin{array}{l}\text { As inovações são as grandes responsáveis } \\
\text { pelo atual resultado positivo da empresa em } \\
\text { meio a toda crise econômica que o país vem } \\
\text { sofrendo. }\end{array}$ & Thomas e Engesser, 2012 \\
\hline $\begin{array}{l}\text { Disseminação do conhecimen- } \\
\text { to }\end{array}$ & $\begin{array}{l}\text { Participação em seminários, feiras, palestras, } \\
\text { workshops, fóruns e demais eventos relacio- } \\
\text { nados ao tema. }\end{array}$ & Vilha, 2010 \\
\hline Gestão da inovação & $\begin{array}{l}\text { Empresas já estão inserindo a inovação em } \\
\text { seus planejamentos estratégicos a fim de } \\
\text { inseri-la de forma efetiva no seu dia a dia. }\end{array}$ & $\begin{array}{l}\text { Prahalad e Krishnan, } 2008 \text { e } \\
\text { Scherer e Carlomagno, } 2009\end{array}$ \\
\hline Dificuldades para inovar & $\begin{array}{l}\text { Alto custo, tempo de maturação, pouca expe- } \\
\text { riência e falta de cultura em inovação. }\end{array}$ & Trott, 2012 \\
\hline
\end{tabular}

Porém, tendo em vista o pouco tempo em que o tema inovação está presente no dia a dia das empresas, todos os entrevistados relataram alguma dificuldade para implementar a inovação, bem como para torná-la realmente parte efetiva e lucrativa na empresa.

Fazer a inovação custa caro ... leva tempo ... tempo é dinheiro. Em épocas de crise no nosso setor, é difícil falar em gastar dinheiro com algo que demore. Por isso que acho uma boa a gente pagar e ter consultoria para dar o norte. .. Dizer exatamente o que e como precisamos fazer (El, 9 de julho de 2019).

Sinto dificuldade em fazer todo o time falar a mesma língua. ... Falar de inovação é muito bonito, mas na prática, no dia a dia, respirar inovação, fazer dela algo contínuo demanda muito das pessoas... nem sempre elas estão a fim (E2, 11 de julho de 2019).

Pessoal tem uma ideia que só eu preciso pensar em inovação ... que é algo de outro mundo (E3, 12 de julho de 2019).

Todo o investimento precisa de um tempo pra dar retorno ... nem sempre a empresa tem tempo de caixa para esperar... isso dificulta o trabalho (E4, 15 de julho de 2019).

Eu valorizo muito o que o pessoal sugere de melhorias, mas tem que estar toda hora cobrando, nem sempre esse processo é dinâmico (E5, 17 de julho de 2019).

A gente teve que reduzir o número de funcionários ... alguns ficaram sobrecarregados de atividades e por isso não conseguem inovar (E6, 17 de julho de 2019).

Às vezes é difícil falar de inovação ... calçado é algo muito tradicional . . . já se tem um jeito de fazer ... é difícil fazer as pessoas do chão de fábrica mudar a forma de pensar. . . Muitas vezes o pai dele ensinou ele a fazer sapato assim.... Se tem muito aquele lema: "sempre foi feito assim" (E7, 19 de julho de 2019). 
Eu vivi minha vida toda em fábrica de sapato ... nunca foi tão difícil fazer sapato como agora. . .. A margem que a gente tem agora é muito baixa ... o jeito é mudar a forma de pensar e fazer. ... A gente está mudando ... buscando ajuda dos centros de pesquisa para poder inovar. . . Não sabemos nem por onde o começar (E8, 19 de julho de 2019).

Eu vejo como se fosse uma guerra na empresa ... de um lado os mais tradicionais que têm resistência às mudanças, e do outro os que buscam uma mudança no jeito de fazer as coisas, porque têm consciência que as coisas mudaram ... que têm medo de perder o emprego.... Então se muda pela dor (E9, 22 de julho de 2019).

As principais dificuldades apresentadas foram com relação a alto custo, tempo de maturação, pouca experiência e falta de cultura em inovação, o que dificulta a aceitação por grande parte da equipe. Essas dificuldades vão ao encontro dos principais motivos que levam ao fracasso ou ao sucesso apresentados por Trott (2012), que confirma que entre os principais motivos para as inovações não serem bem-sucedidas estão os altos custos e a falta de experiência das empresas nos processos de inovação.

Como forma de mitigar as referidas carências do processo de gestão da inovação, as empresas aliaram-se ao Núcleo de Inovação Tecnológica (NIT - IBTeC), localizado na Cidade de Novo Hamburgo, que atualmente é o mais completo complexo de laboratórios de pesquisas e ensaios do sistema coureiro-calçadista nacional. A referida entidade é à qual se refere o entrevistado E8 no seu relato, exposto anteriormente. A prestação de serviços especializados como ensaios, testes e validações é o principal foco do IBTeC, sendo estes sinalizados pelos entrevistados como serviços de suportes de grande relevância para o avanço de suas inovações. O entrevistado El ressalta a importância do auxílio na implantação de serviços de gestão da inovação nas empresas, tendo em vista que poucas possuem essa gestão profissionalizada.

Por meio da referida estrutura, os entrevistados sinalizaram que a participação de palestras e treinamentos de curto prazo são as práticas que atualmente mais contribuem para a adoção de novos conhecimentos e interação com outras empresas do mesmo segmento. Conforme Coral et al. (2009), Barbieri et al. (2009) e Guimarães (2011), a ciência e a tecnologia possuem uma forte ligação, o que torna as pesquisas de universidades muito importantes para o avanço técnico das empresas. $O$ entrevistado E5 acredita que por meio de projetos e programas conjuntos de $P \& D$ entre as empresas, universidade e o Instituto, aumenta-se a possibilidade de gerar novos produtos, pois por intermédio dessa integração é possível ter acesso a tecnologias e informações que certamente as empresas não teriam acesso individualmente. 


\section{CONSIDERAÇÕES FINAIS}

A partir desta pesquisa foi possível identificar especificidades, necessidades e carências do processo de gestão da inovação do setor coureiro-calçadista de nove empresas localizadas no Município de Novo Hamburgo, no Estado do Rio Grande do Sul, ao Sul do Brasil. Como principais resultados destaca-se o quanto as referidas organizações ainda se encontram em estágios iniciais no que diz respeito ao processo de gestão da inovação. Cumpre destacar que o setor em tela é conhecido em todo o Brasil como um setor individualista, conservador e com uma alta resistência a mudanças, o que transforma o processo de inovação mais complexo.

Contudo, os entrevistados reconhecem o potencial de diferenciação que está implícito no processo de inovação, mas ressaltam o alto custo, a pouca experiência e a falta da cultura da inovação como as principais barreiras na adoção de práticas de inovação. Para facilitar as atividades que envolvem a gestão diária da inovação, qualificar e desenvolver novas competências, tanto nos líderes quanto nos demais colaboradores, estabelecer relações externas, bem como reduzir custos, os gestores sinalizaram que suas referidas empresas participam do Núcleo de Inovação Tecnológica do Instituto Brasileiro de Tecnologia do Couro, Calçado e Artefatos (IBTeC), localizado na Cidade de Novo Hamburgo.

No tocante às limitações da pesquisa, destaca-se a coleta de evidências realizada por meio de entrevistas em profundidade. A amplitude das respostas depende do conhecimento e da experiência tanto dos entrevistados quanto dos pesquisadores, com provável viés e influência na interpretação das evidências que emergiram do processo de análise. Outro fator limitante refere-se à impossibilidade de generalização analítica dos resultados obtidos, estando restrita à realidade investigada.

Entretanto, acredita-se que o estudo a presenta importantes análises para a compreensão de um processo estratégico voltado para a inovação, facultando o desenvolvimento de novos estudos sobre o referido tema. Sendo assim, propõe-se a ampliação do estudo, por meio de estudo de caso múltiplo, com foco na identificação de fatores internos que podem tanto favorecer quanto dificultar a consolidação do modelo de inovação no setor industrial em tela.

\section{REFERÊNCIAS}

Associação Brasileira das Indústrias de Calçados. (2020). Relatório Setorial. Indústria de Calçados. http://abicalcados.com.br/publicacoes/relatorio-setorial 
Associação Brasileira das Indústrias de Calçados. (2021, fevereiro). ABINFORMA: Informativo da Associação Brasileira das Indústrias de Calçado. https://www.abicalcados.com. $\mathrm{br} / \mathrm{midia} /$ informativo/arquivos/16127857341927.pdf

Barbieri, J. C., Álvares, A. C., \& Cajazeira, J. E. R. (2009). Gestão de ideias para inovação contínua. Bookman.

Bardin, L. (2016). Análise de conteúdo. Edições 70.

Brabandere, L. (2006). O lado oculto das mudanças. Elsevier.

Bessi, V. G., Oberherr, G., \& Oliveira, C. F. (2019). Estímulos e barreiras para a promoção de uma cultura da inovação em uma empresa calçadista. Desenvolve Revista de Gestão do Unilasalle, 8(3), 63-78.

Coral, E., Ogliari, A., \& Abreu, A. F. (2009). Gestão integrada da inovação: Estratégia, organização e desenvolvimento de produtos. Atlas.

Davila, G. A., Durst, S., \& Varvakis, G. (2018). Knowledge absorptive capacity, innovation, and firm's performance: Insights from the South of Brazil. International Journal of Innovation Management, 22(2), 1850013.

Davila T., Epstein M. J., \& Shelton R. (2012). Making innovation work: How to manage it, measure it, and profit from it. FT Press.

Frishammar, J., Richtnér, A., Brattström, A., Magnusson, M., \& Björk, J. (2019). Opportunities and challenges in the new innovation landscape: Implications for innovation auditing and innovation management. European Management Journal, 37(2), 151-164.

Guimarães, S. K. (2011, setembro-dezembro). Produção do conhecimento científico e inovação: Desafios do novo padrão de desenvolvimento. Cad. CRH, 24(63).

Hair, J. F., Babin, B., Money, A. H., \& Samouel, P. (2005). Fundamentos de métodos de pesquisa em administração. Bookman.

Instituto Brasileiro de Geografia e Estatística. (2014). PINTEC - Pesquisa Industrial de Inovação Tecnológica. https://biblioteca.ibge.gov.br/visualizacao/livros/liv99007.pdf

Jannuzzi, C. S. C., Falsarella, O. M., \& Sugahara, C. R. (2016). Gestão do conhecimento: Um estudo de modelos e sua relação com a inovação nas organizações. Perspectivas em Ciência da Informação, 21(1), 97-118. 
Marconi, M. A., \& Lakatos, E. M. (2011). Metodologia científica. (6a ed. rev. ampl.). Atlas.

Oliveira, C. A. A., Araújo, M. S. B., Nascimento, P. S., Ferreira, L. C., \& Rossi, A. L. (2009). Estratégias de crescimento econômico: Auferindo vantagens competitivas através da inovação. Anais do Encontro da ANPAD, São Paulo, 33.

Organização para Cooperação e Desenvolvimento Econômico. (2005). Manual de Oslo: Diretrizes para coleta e interpretação de dados sobre inovação (3a ed.). http://www.mct. gov.br/index.php/content/view/4639.html

Polkinghorne, D. (2007). Validity issues in narrative research. Qualitative Inquiry, 13(4), 471486.

Prahalad, C. K., \& Krishnan, M. S. (2008). A nova era da inovação. Campus.

Roesch, S. M. A. (2005). Projetos de estágios e de pesquisa em Administração: Guia para estágios, trabalhos de conclusão, dissertações e estudo de caso (3a ed.). Atlas.

Santana, J. R., Silva Teixeira, A. L., Rapini, M. S., \& Esperidião, F. (2020). Financiamento público à inovação de empresas no Nordeste: Uma análise setorial à luz dos objetivos das políticas industrial e de inovação. Revista Econômica do Nordeste, 51(1), 161-179.

Scherer, F. O., \& Carlomagno, M. S. (2009). Gestão da inovação na prática: Como aplicar conceitos e ferramentas para alavancar a inovação. Atlas.

Schumpeter, J. A (1982). Teoria do desenvolvimento econômico: Uma investigação sobre lucros, capital, crédito, juro e o ciclo econômico. Abril Cultural.

Souza, V., Paula. N. M., \& Fuck, M. P. (2012). Os desafios da Industria Calçadista Brasileira: Competir ou proteger. Revista Economia \& Tecnologia, 8(4), 93-100.

Thomas, E., \& Engesser, M. N. (2012). Socialização de conhecimentos para a inovação: $O$ nível de compartilhamento com empresas parceiras. Anais do Encontro da ANPAD, Rio de Janeiro, 36. http://www.anpad.org.br/admin/pdf/2012_EOR959.pdf

Tidd, J., \& Bessant, K. (2015). Gestão da inovação (5a ed.). Bookman.

Trantopoulos, K., von Krogh, G., Wallin, M. W., \& Woerter, M. (2017). External knowledge and information technology: Implications for process innovation performance. MIS quarterly, 4l(1), 287-300. 
Trott, P. (2012). Gestão da inovação e desenvolvimento de novos produtos (4a ed.). Bookman.

Vilha, A. M. (2010). Gestão da inovação nas empresas. PDS Diadema - Plástico \& Borracha.

Xavier, A. F., Naveiro, R. M., Aoussat, A., \& Reyes, T. (2017). Systematic literature review of eco-innovation models: Opportunities and recommendations for future research. Journal of Cleaner Production, 149, 1278-1302.

West, J., \& Bogers, M. (2017). Open innovation: Current status and research opportunities. Innovation, 19(1), 43-50.

Zawislak, P. A., Borges, M., Wegner, D., Santos, A., \& Castro-Lucas, C. (2008). Towards the innovation function. Journal of Technology Management \& Innovation, 3(4), 17-30. 